\title{
Analysis of wheel-rail contact under partial slip and low speed conditions
}

\author{
Y. Özdemir*, P. Voltr** \\ *University of Pardubice, Studentska 95, 53210 Pardubice, Czech Republic, E-mail: yalcinozdemir@anadolu.edu.tr \\ **University of Pardubice, Studentska 95, 53210 Pardubice, Czech Republic, E-mail: petr.voltr@upce.cz \\ cross $^{\text {ref }}$ http://dx.doi.org/10.5755/j01.mech.23.1.13779
}

\section{Introduction}

Contact mechanics is outstanding point of the Railway engineering. Components of the forces which occur on the contact interface directly affect vehicle traction, material degradation of the railway track parts and vehicle dynamics. Rolling contact fatigue, wear of rail and wheel, stress distributions on contact patch and dynamic response of railway vehicles are prevalently researched topics, which are related to wheel and rail contact.

Stress distribution on the contact interface is an effective factor for the normal and tangential problems. The normal problem consist of finding the pressure and dimensions of the contact area. The first examination of the normal problem was performed by Hertz, who used some assumptions such as full elasticity, half space approach etc. [1]. Tangential contact phenomena including the relationship between components of creepage and tangential forces were investigated by various researchers amongst whom J.J. Kalker contributed prominently to wheel-rail rolling contact theory [2]. Early use of finite element (FE) method in 2D rolling contact problems was stated in [3]. Yan and Fischer [4] analyzed application of Hertz contact theory on real wheel-rail contact problem. Srivastava et al. [5] carried out analytical approach based on Hertz contact theory and (FE) analysis in wheel-rail contact. Effects of different parameters of wheel and rail profiles was examined into normal contact problem. Arslan and Kayabaşı [6] researched foundation of wheel-rail contact in (FE) analysis and described flowchart of 3D solutions.

3-D wheel-rail contact simulations have been performed with the advances in capacity of computers. Zhao and $\mathrm{Li}$ [7] proposed 3D transient frictional rolling contact model to investigate the stress distribution over the contact patch $(140 \mathrm{~km} / \mathrm{h}$ translational velocity). Cylindrical shaped wheel profile was considered in the study. In order to validate maximum pressure and contact area results which were result of (FE) model, Hertz contact theory and Contact software [8] were implemented. Furthermore, 3D elastic-plastic rolling contact model was set up to focus on stick-slip areas [9]. Vo et al. [10] used elastic-plastic material model to observe stress distribution and material response under various adhesion conditions. Canted and non-canted rail structure were utilized in order to compare effects of cant angle, also $80 \mathrm{~km} / \mathrm{h}$ travel velocity was applied. Result of FE analysis were compared with respect to Contact software and Polach's model by means of normal and tangential forces. Zhao et al. [11] examined a 3-D rolling contact model to simulate contaminated surface of rail at high speed conditions $(300 \mathrm{~km} / \mathrm{h})$. Zhao et al. [12] observed wheel and rail interaction at high speed railroad having short pitch rail corrugations. Wiest et al. [13] evaluated the contact pressure, contact area and penetration depth at wheel-rail/switch contact by means of FE analysis.

The main target of this study is to assess FE analysis procedure and effective parameters of 3-D rolling contact using FE analysis in low adhesion and low speed conditions in which there is lack of such an analysis from authors' knowledge. In addition, for low speed conditions, different from previous studies transition in coefficient of friction (COF) from high to low level was observed. So as to validate results of study, methods which have been used by previous researchers were implemented. Not only linear elastic mechanical properties of material was used but also elastic-plastic material model was considered.

\section{Material and methods}

\subsection{Modelling of wheel-rail rolling contact}

Real wheel profiles have been used in our work, however cylindrical wheel profile is used in this study for purposes of comparability with methods based on Hertzian geometry and for elimination of small components of geometrical spin. The wheel with $920 \mathrm{~mm}$ rolling diameter and commonly used theoretical rail profile UIC 60 [14] were set up in order to simulate real contact geometry. A non-canted straight rail with $1600 \mathrm{~mm}$ of length and whole wheel body were modelled. Schematically illustration of rolling contact assembly is given in Fig. 1. The $\mathrm{x}$ axis of model was placed along the rail extrude direction and the $\mathrm{z}$ axis was defined at the vertical direction of the rail bottom.

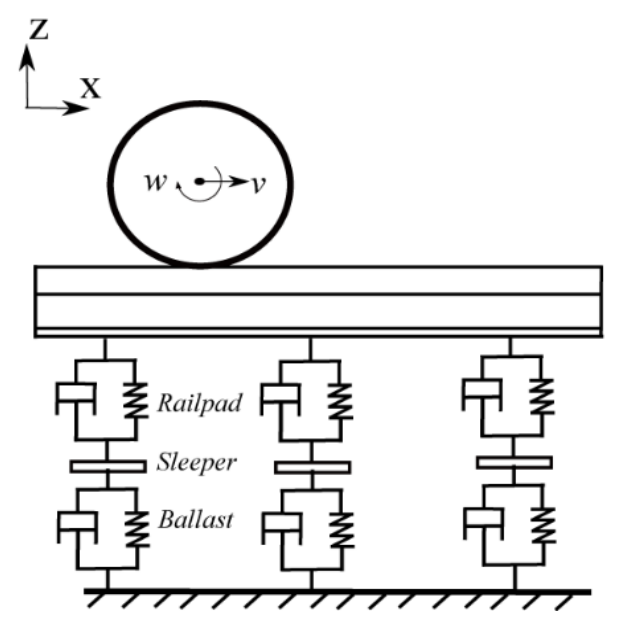

Fig. 1 Schematic illustration of rolling contact model 
Undesired vibrations take place in simulations due to effects of rolling contact motion. A flexible and damped subtrack system was added with the purpose of preventing those motions. Parameters subtrack system, which were implemented in previous study [15], are presented in Table 1.

Table 1

Properties of subtrack system [15]

\begin{tabular}{|l|l|l|}
\hline Components & Parameters \\
\hline Railpad & Stiffness, N/m & $200 \times 10^{6}$ \\
\cline { 2 - 3 } & Damping, Ns/m & $50 \times 10^{3}$ \\
\cline { 2 - 3 } & Length, $\mathrm{m}$ & 0.0075 \\
\hline Sleeper & Mass, kg & 314 \\
\hline \multirow{3}{*}{ Ballast } & Stiffness, N/m & $125 \times 10^{6}$ \\
\cline { 2 - 3 } & Damping, Ns/m & $310 \times 10^{3}$ \\
\cline { 2 - 3 } & Height, $\mathrm{m}$ & 0.25 \\
\hline
\end{tabular}

$$
\xi=\frac{\omega R-V}{(\omega R+V) / 2}
$$

Pure longitudinal creepage was described with the value of 0.003 which, for theoretical steel-to-steel tangential flexibility means the mode of partial sliding. Translational and angular velocity components of wheel motion were determined according to Eq. (1) in which $\xi, \omega, V$ and $R$ are the longitudinal creepage, angular velocity of wheel around the axis of axle, translational velocity of wheelset and radius of wheel, respectively. Since low adhesion and low speed characteristics were considered, $3000 \mathrm{~mm} / \mathrm{s}(10.8 \mathrm{~km} / \mathrm{h})$ the translational and $6.5414 \mathrm{rad} / \mathrm{s}$ of rotational velocity were selected. Lateral and spin creepage was not present.

The procedure of the FE solution is summarised as a flowchart in Fig. 2. The chart represents the steps of rolling contact FE solutions.

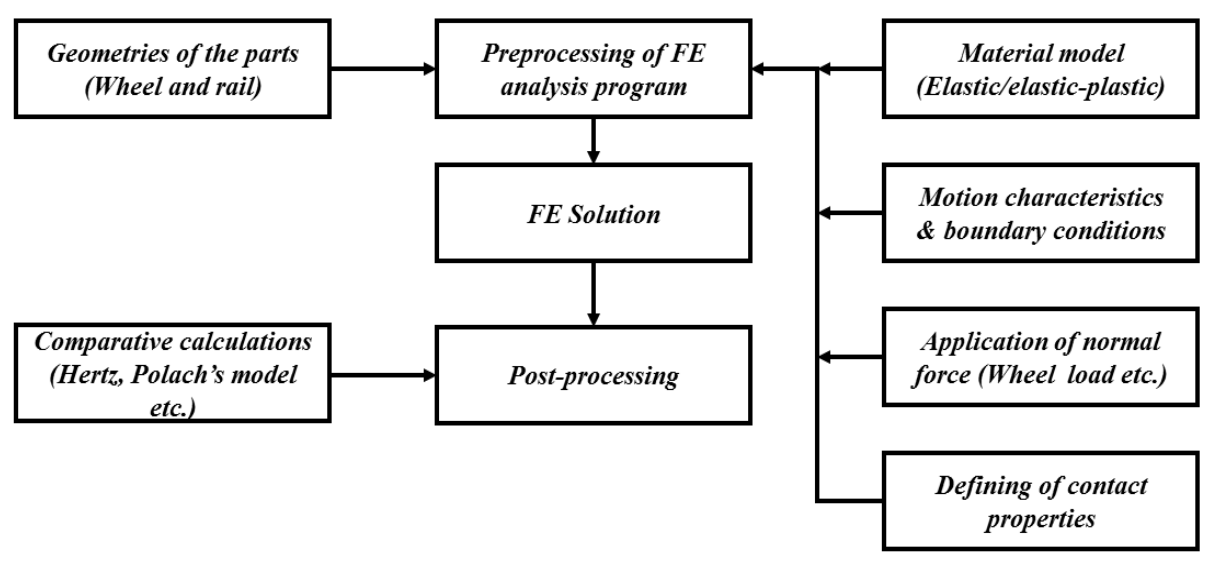

Fig. 2 Steps of 3-D rolling contact FE analysis

\subsection{Numerical modelling}

Commercial numeric solution package program ABAQUS ${ }^{\mathrm{TM}} /$ implicit was utilized in the simulations [16]. The whole assembly was meshed with C3D8R reduced integrate solid element (Fig. 3). Almost whole geometry has coarse structure, only stress measurement zone (SMZ) has finer mesh structure. Different mesh sizes were applied to SMZ such as 1, 0.8, 0.6, and $0.4 \mathrm{~mm}$. Duration of simulation was divided in two steps. In the first step, normal force was applied on reference point which is located on the central position of wheel with respect to time dependent amplitude without motion. Values of that motion reached desired level with time before the bodies came into contact over the SMZs.

The parameters of subtrack system were embedded in spring and damper system, also top points of the system were connected with bottom surface of rail via constraint. Width of the coupled area is $130 \mathrm{~mm}$ and distance between two subtrack structures is $600 \mathrm{~mm}$ [10]. Point to point connection type [16] was used to define rail pad having $7.5 \mathrm{~mm}$ length (Table 1). In order to assemble the ballast part of the track, same connection definition was applied. Sleeper was defined as isotropic point mass.

Normal and tangential interaction was defined in wheel-rail connection. Surface of wheel and target surface of rail were described as "master" and "slave", respectively. Normal force was transmitted through the normal contact algorithm, and tangential contact algorithm was selected to add tangential interaction properties [16]. COF was assumed to be constant (0.4) and isotropic (only changing suddenly at the transition between high and low adhesion zones, as described below). Surface properties of the parts are accepted as smooth, and surface roughness wasn't considered. So as to observe effects of friction on distribution of normal stress and contact patch, a frictionless analysis was also conducted. Necessary boundary conditions were selected in the rectangular coordinate system. Lateral motion of wheel was restricted and bottom of the rail was free to move in the vertical direction.

Surface of the track can be contaminated from environmental conditions or affected by environment effects like leaf layer etc. that gives rise to unstable surface properties of the track, so adhesion properties are directly influenced.

In addition to previous examinations, transient friction properties are performed. SMZ was divided into two parts; COF is equal to 0.06 and 0.03 , respectively. Model of the zone is presented in Fig 4. These friction properties, which were defined as low and very low friction condition, are given in the literature [17]. 


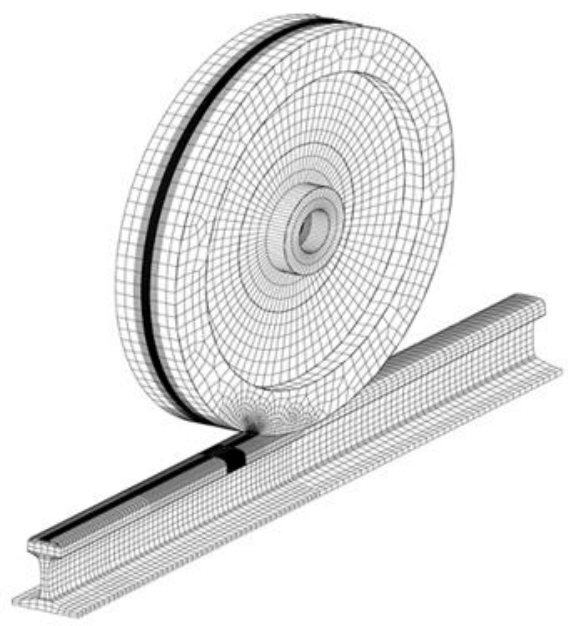

a

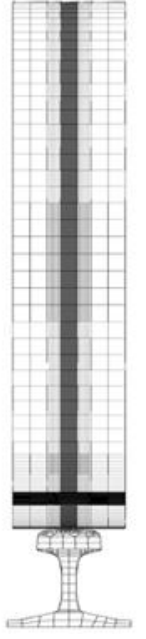

b

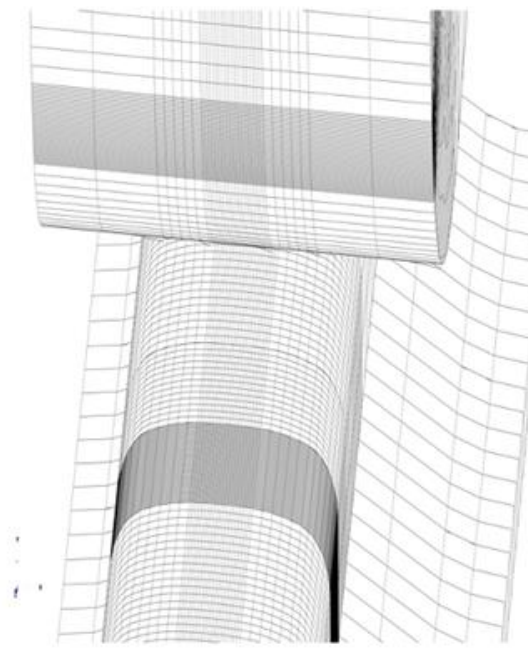

c

Fig. 3 Meshed FE Model: a - Isometric; b - Front; c - SMZs

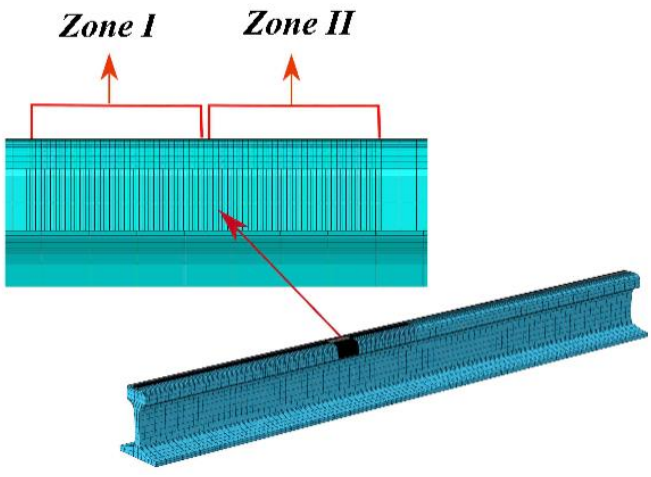

Fig. 4 Illustration of SMZ which has two different COF

\subsection{Wheel and rail material}

Linear elastic and bi-linear elastic-plastic material models were considered in the examinations. All of them are given in Table 2. The bi-linear material model is determined by Zhao X. \& Li Z. [9] based on the parameters given by previous studies $[18,19]$.

Gravitational force effect was neglected. The elastic-plastic material model has a constant tangent modulus.

Values of material properties $[9,18,19]$

Table 2

\begin{tabular}{|l|c|}
\hline Parameters & Values \\
\hline Young's modulus $E, \mathrm{GPa}$ & 210 \\
\hline Poisson's ratio, $v$ & 0.3 \\
\hline Density $\rho, \mathrm{kg} / \mathrm{m}^{3}$ & 7800 \\
\hline Yield strength $\sigma_{y}, \mathrm{MPa}$ & 500 \\
\hline Tangent modulus $T, \mathrm{GPa}$ & 21 \\
\hline
\end{tabular}

\section{Results and discussion}

\subsection{Validation procedure}

In the literature, researchers evaluated various ways for the aim of validating their results. Pressure distributions were compared with Hertz contact theory and Contact software [8] that was used also to validate shear stress distributions. Polach's model [20,21] and Kalker's studies implemented in the Contact software were used for comparison of tangential forces. In this research, all of these methods were applied and their results were listed in Table 3.

The foundation of the Polach's model depends on integration of the shear stress distribution over the contact patch to derive the traction force. The shape of the contact is accepted to be elliptical. Dimensions of the area and normal stress distribution are imported from Hertz contact theory. The tangential force $(F)$ defined by Polach (without spin) is given Eq. (2). $Q$ is the wheel load, $s_{\mathrm{x}}$ is longitudinal constituent of the total creep, $G$ is the shear modulus [20, $21]$ and $c_{j j}$ is the Kalker's coefficient [22].

$$
\begin{aligned}
& F=\left[\frac{2 Q \mu}{\pi}\left(\frac{\varepsilon}{1+\varepsilon^{2}}+\tan ^{-1} \varepsilon_{x}\right)\right] ; \\
& \varepsilon_{x}=\frac{1}{4} \frac{G \pi a b c_{11}}{Q \mu} s_{x} .
\end{aligned}
$$

Table 3

Results for validation

\begin{tabular}{|l|c|c|c|}
\cline { 2 - 4 } \multicolumn{1}{c|}{} & Polach & Contact & Hertz \\
\hline Normal force, $\mathrm{kN}$ & 100 & 100 & 100 \\
\hline Traction force, $\mathrm{kN}$ & 30.461 & 30.430 & ----- \\
\hline Max. contact pressure, $\mathrm{MPa}$ & ----- & 1234.5 & 1237.6 \\
\hline Max shear stress, MPa & ----- & 488.81 & ---- \\
\hline Total contact area, $\mathrm{mm}^{2}$ & ----- & 122.25 & 121.21 \\
\hline
\end{tabular}

Calculation of the Hertz contact theory [1] depends on curvatures of the bodies in contact. Wheel has cylindrical shape so lateral curvature of the wheel is infinite. Additionally, sketch of the rail extruded as straight resulting in curvature of the rail is infinite in longitudinal direction.

\subsection{Numerical results}

All of the outputs of the computations which include normal force, traction force, maximum contact pressure and area of contact are given in Table 4.

Different mesh sizes were assigned for whole 
model at simulations. Influence of the mesh size on contact parameters were observed. In addition, an element edge size
$(1 \mathrm{~mm})$ was examined to figure out difference in frictional (Fig. 6) and frictionless rolling contact.

Table 4

Outputs of numerical calculations for elastic and elastic-plastic material models

\begin{tabular}{|c|c|c|c|c|c|c|}
\hline & \multicolumn{6}{|c|}{ Mesh sizes, mm } \\
\hline & $\begin{array}{c}1 \times 1 \text { (fric- } \\
\text { tionless) }\end{array}$ & $1 \times 1$ & $0.8 \times 0.8$ & $0.6 \times 0.6$ & $0.4 \times 0.4$ & $\begin{array}{c}\text { Elastic }- \text { Plastic } \\
\text { FEM } 0.4 \times 0.4\end{array}$ \\
\hline Max. Pressure, MPa & 1205 & 1204 & 1243 & 1248 & 1231 & 1038 \\
\hline Max Shear stress, MPa & ----- & 435.9 & 465.1 & 472.8 & 481.1 & 349.1 \\
\hline Total contact area, $\mathrm{mm}^{2}$ & 138.389 & 137.37 & 137.075 & 134.948 & 132.373 & 137.46 \\
\hline Normal force, $\mathrm{kN}$ & 99.894 & 99.942 & 99.977 & 99.958 & 100.2 & 100.08 \\
\hline Traction force, $\mathrm{kN}$ & ----- & 27.574 & 28.508 & 29.622 & 30.566 & 26.255 \\
\hline
\end{tabular}

All of the results were taken from SMZ. That is why the zone has finer mesh structure, whereas other sections has coarse mesh density.

First of all, there is no distinctive difference in results of frictionless and constant COF in the normal problem. Only, small change is seen in value of total contact area. In the Table 4, outputs of four different mesh sizes are given. As for the maximum contact pressure, there is an inverse relationship between mesh density and maximum contact pressure. Higher contact pressure occurs with finer mesh density, but there is difference for $0.4 \mathrm{~mm}$ mesh size. Also result of that is closer to analytic calculation Hertz and Contact software. Furthermore, the same situation is observed for the maximum contact shear stress. Maximum shear stress level of the $0.8 \mathrm{~mm}$ meshed model is $30 \mathrm{MPa}$ higher than $1 \mathrm{~mm}$ meshed model, but there is approximately $9 \mathrm{MPa}$ difference between $0.4 \mathrm{~mm}$ and $0.6 \mathrm{~mm}$ mesh sizes.

Total contact area has decreasing trend with finer mesh structure, and results of the coarse and finer mesh structures are close. Theoretical value of the normal force must equal to applied vertical load. Even so, $100 \mathrm{kN}$ total normal force, which occurs on the contact patch, cannot be obtained over the contact area due to small fluctuations arising from undesired vibrations and motions on parts.

In addition to linear elastic material properties, elastic-plastic material model was employed to rolling contact simulation. In the plastic analysis, remarkable differences were obtained. The total contact area is bigger than in elastic analysis, and maximum pressure is lower in elasticplastic analysis. As it seen on Fig. 5, shapes of the contact areas are different. The geometry of contact that is resultant of the elastic analysis is elliptical. However, the geometry of the elastic-plastic analysis isn't elliptical. Zhao et al. called that geometry as "egg shape" [9].
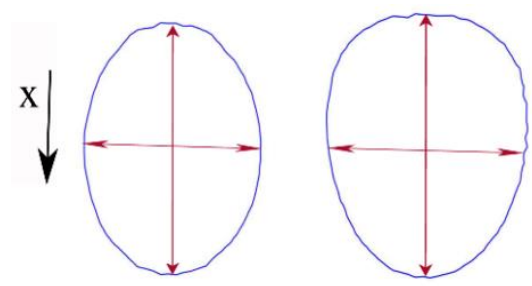

Fig. 5 Illustration of contact areas in linear elastic and elastic-plastic rolling contact simulations for $0.4 \times 0.4 \mathrm{~mm}^{2}$ meshed model
Plasticity give rise to not only geometric change in trailing edge of the contact region but also difference from corresponding linear elastic simulation.

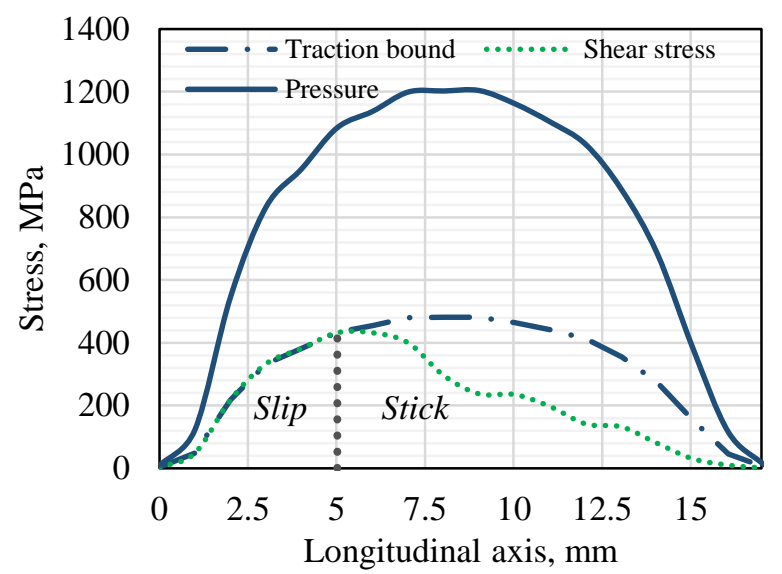

Fig. 6 Longitudinal stress distribution of $1 \times 1 \mathrm{~mm}^{2}$ meshed model over the central position of contact area

Findings of the Polach's model, Contact software and Hertz contact theory are compatible between each other. This shows that calculation of them at the same analysis is not necessary. When the results are compared with FE analysis, difference in value of the contact area is interesting. That is approximately $14 \mathrm{~mm}^{2}$. Reason of that can depend on calculation type of contact area in the ABAQUS ${ }^{\mathrm{TM}}$ [16]. On the other hand half space assumption and others are not used in FE analysis. Maximum pressure level of $0.4 \times 0.4$ $\mathrm{mm}^{2}$ meshed model is close to result of the Hertz contact theory and Contact software.

As the mesh structure gets finer, value of the maximum shear stress increases in FE analysis. In addition to previous results which include constant COF, multi-frictional SMZ was simulated. In the study, effects of the suddenly changed COF were taken into account. Normal and tangential forces were particularly examined. Normal and traction force values were taken from the contact patch during simulation.

Fig. 7 gives normal and traction force values of rolling contact for multi-friction SMZ. When the wheel comes to border between two zones, value of normal force is obtained from zone I and zone II, respectively. It can be seen that value of total value normal force doesn't change. But for the traction force, traction force suddenly decreased. Effects of very low frictional conditions on traction 
of vehicle are understood from traction force distribution. The effects of very low condition are given in next Fig. 8. Similar results were obtained from $0.03 \mathrm{COF}$ used analysis.

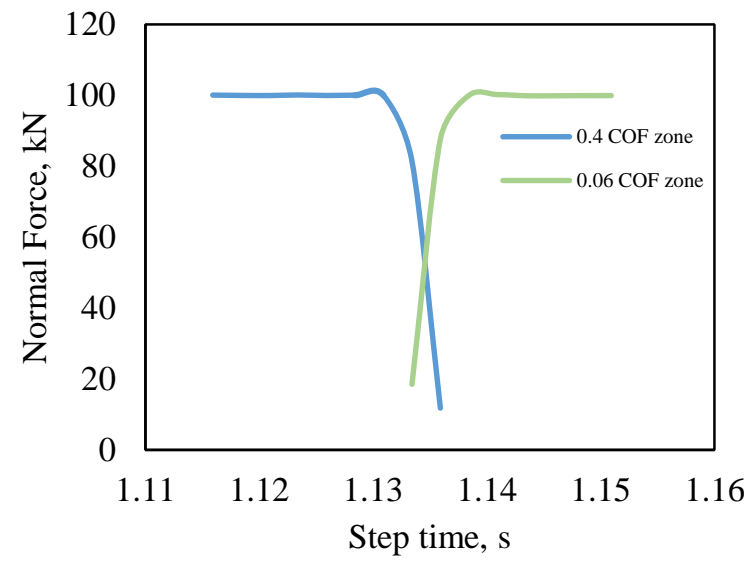

However, traction force corresponding to 0.03 is of course lower that for 0.06 .

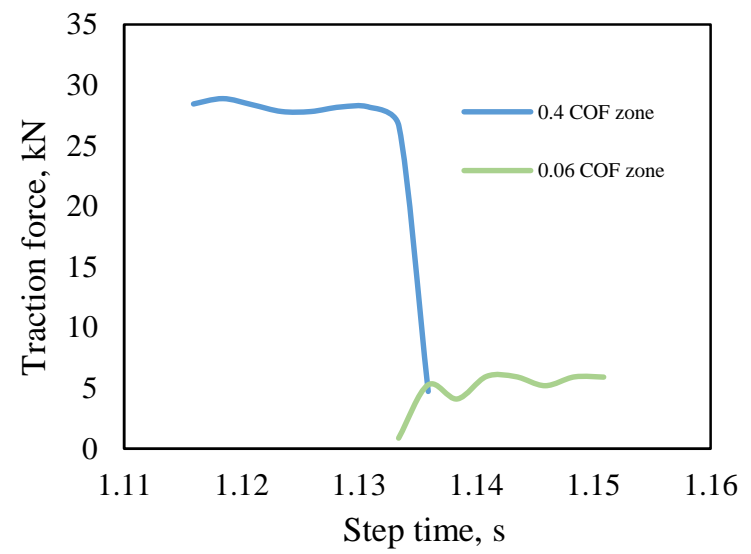

Fig. 7 Distribution of normal and traction forces on the multi-frictional zone
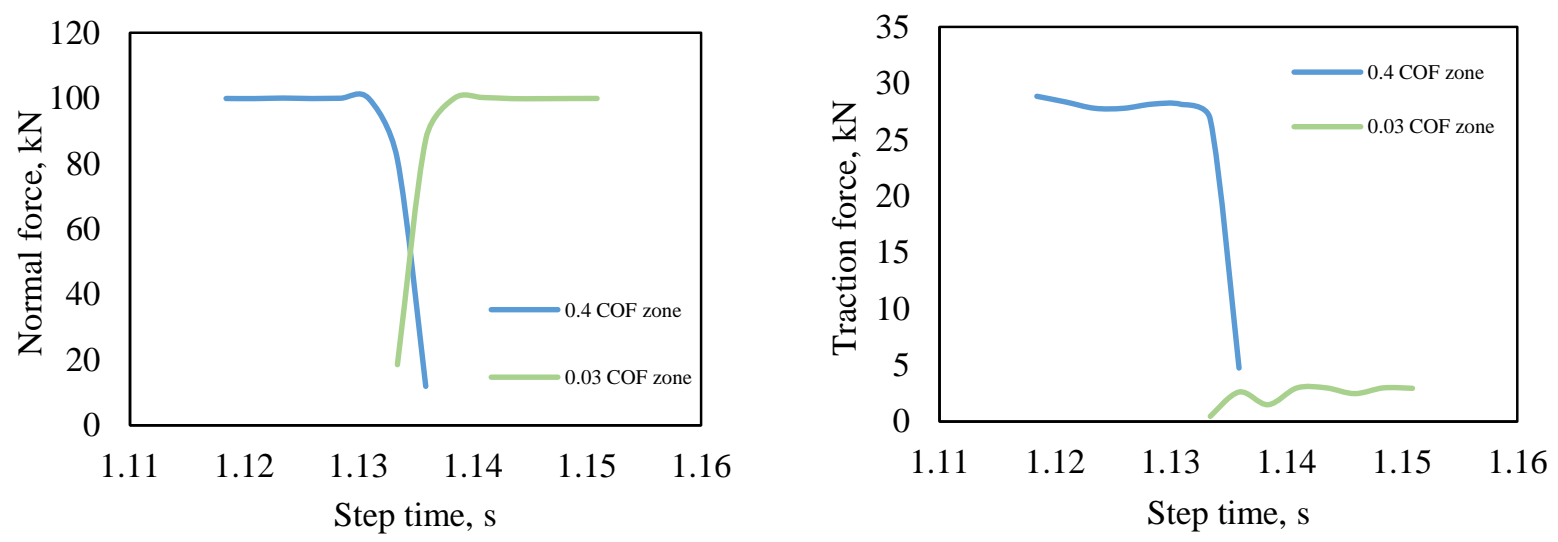

Fig. 8 Distribution of normal and traction forces on the multi-frictional zone

\section{Conclusion}

As results of the simulation which were carried out in low speed and low adhesion conditions, some outputs were derived:

- mesh density is an effective parameter on the traction bound;

- solution with coarse mesh such as $1 \mathrm{~mm}$ should be considered because of the time cost of the analysis;

- in order to validate results of simulations which has elastic material behaviour, each of the methods that were computed in the study can be used;

- COF suddenly change in contaminated area on the track. Traction force was significantly is affected owing to contamination.

Irregular track surface, small deformations on the wheel surface, and effects of the cyclic deformation on traction bound may be worked in further research.

\section{References}

1. Hertz, H. 1882. Über die Berührung fester elastischer Körper, Journal Für die Reine und Angewandte Mathematik 92: 156-171.

2. Kalker, J.J. 1990. Three-Dimensional Elastic Bodies in Rolling Contact, Kluwer Academic Publisher, 314 p. http://dx.doi.org/10.1007/978-94-015-7889-9.
3. Bogdanski, S.; Olzak, M.; and Stupnicki J. 1996. Numerical stress analysis of rail rolling contact fatigue cracks, Wear 191(1-2): 14-24. http://dx.doi.org/10.1016/0043-1648(95)06685-3.

4. Yan, W.; Fischer, F.D. 2000. Applicability of the Hertz contact theory to rail-wheel contact problems, Archive of Applied Mechanics, 70(4): 255-268. http://dx.doi.org/10.1007/s004199900035.

5. Srivastava, J.P.; Sarkar, P.K.; Ranjan, V. 2014. Contact stress analysis in wheel-rail by hertzian method and finite element method, Journal of The Institution of Engineers (India) Series C 95(4): 319-325. http://dx.doi.org/10.1007/s40032-014-0145-x.

6. Arslan, M.A.; Kayabaşı, O. 2012. 3-D Rail-Wheel contact analysis using FEA, Advances in Engineering Software 45(1): 325-331. http://dx.doi.org/10.1016/j.advengsoft.2011.10.009.

7. Zhao, X.; Li, Z. 2011. The soltion of frictional wheelrail rolling contact with a $3 \mathrm{D}$ transient finite element model: Validation and error analysis, Wear 271(12): 444-452. http://dx.doi.org/10.1016/j.wear.2010.10.007.

8. Vollebregt, E.A.H. 2015. User guide for CONTACT, Rolling and sliding contact with friction, Technical report TR09-03, VORtech BV, Delft, The Netherland.

9. Zhao, X.; Li, Z. 2015. A three-dimensional finite element solution of frictional wheel-rail rolling contact 
in elasto-plasticity, Proceedigs of the Ins. Of Mec. Eng. Part J Journal of Engineering Tribilogy 229(1): 86-100. http://dx.doi.org/10.1177/1350650114543717.

10. Vo, K.D.; Tieu, A.K.; Zhu, H.T.; Kosasih, P.B. 2014. A 3D dynamic model to investigate wheel-rail contact under high and low adhesion, International Journal of Mechanical Sciences 85: 63-75.

http://dx.doi.org/10.1016/j.ijmecsci.2014.05.007.

11. Zhao, X.; Wen, Z.; Zhu, M.; Jin, X. 2014. A study on high-speed rolling contact between a wheel and contaminated rail, Vehicle System Dynamics: International Journal of Vehicle Mechanic and Mobility. 52(10): 1270-1287. http://dx.doi.org/10.1080/00423114.2014.934845.

12. Zhao, X.; Wen, Z.; Wang H.; Jin, X.; Zhu, M. 2014. Modelling of high-speed wheel-rail rolling contact on a corrugated rail and corrugation development, Journal of Zhejiang University-SCIENCE A (Applied Physics \& Engineering) 15(12): 946-963.

http://dx.doi.org/10.1631/jzus.A1400191.

13. Wiest, M.; Kassa, E.; Daves, W.; Nielsen, J.C.O.; Ossberger, H. 2008. Assessment of methods for calculatin contact pressure in wheel-rail/switch contact, Wear 265 (9-10): 1439-1445. http://dx.doi.org/10.1016/j.wear.2008.02.039.

14. 13674-1:2011 EN. Railway applications-Track-RailPart 1, 2011.

15. Steffens D.M., 2005. Idenfication and development of a model of railway track dynamic behaviour [master thesis], Queensland University of Technology.

16. ABAQUS ver 6.13, user's manuel, Dassault Sys, Simulia (2013).

17. Ward, C.P.; Goodall, R.M.; Dixon, R.; Charles, G.A. 2012. Adhesion estimation at the wheel-rail interface using advanced model-based filtering, Vehicle System Dynamics: International Journal of Vehicle Mechanic and Mobility 50(12): 1797-1816. http://dx.doi.org/10.1080/00423114.2012.707782.

18. Johansson, G.; Ahlström J; Ekh, M. 2006. Parameter identification and modeling of large ratcheting strains in carbon steel. Computers \& structures 84(15-16), 10021011 .

http://dx.doi.org/10.1016/j.compstruc.2006.02.016.
19. Esveld, C. 2001, Modern railway track, $2^{\text {nd }}$ edn., Zaltbommel, The Netherlands, MRT Productions. 296298 p.

20. Polach, O. 2005. Creep forces in simulations of traction vehicles running on adhesion limit, WEAR 258(78): 992-1000. http://dx.doi.org/10.1016/j.wear.2004.03.046.

21 Polach, O. 1999. A fast wheel-rail forces calculation computer code, Vehicle System Dynamics: International Journal of Vehicle Mechanic and Mobility. Suppl. 33: 728-739.

22 Kalker, J.J. 1967. On the rolling contact of two elastic bodies in the presence of dry friction, Doctoral Thesis, Delft University of Technology.

\section{Y. Özdemir, P. Voltr}

\section{ANALYSIS OF WHEEL-RAIL CONTACT UNDER PARTIAL SLIP AND LOW SPEED CONDITIONS}

$\mathrm{S} \mathrm{u} \mathrm{m} \mathrm{m} \mathrm{a} \mathrm{r} \mathrm{y}$

The paper analyzes applicability of rolling contact simulation in low speed and adhesion conditions. Additionally, transition zone of the coefficient of friction (COF) is implemented. Effects of the $\mathrm{COF}$ are examined to the forces which are normal and tangential components. Various comparative studies are also computed. Differences between numerical results and results of the comparative studies are observed for validation. The results show that outputs of developed FEM model are compatible with comparative studies. Transition zone of the COF directly affects the traction force at low speed conditions.

Keywords: Finite element method, rolling contact, wheelrail contact, low adhesion.

Received December 04, 2015 Accepted February 06, 2017 